
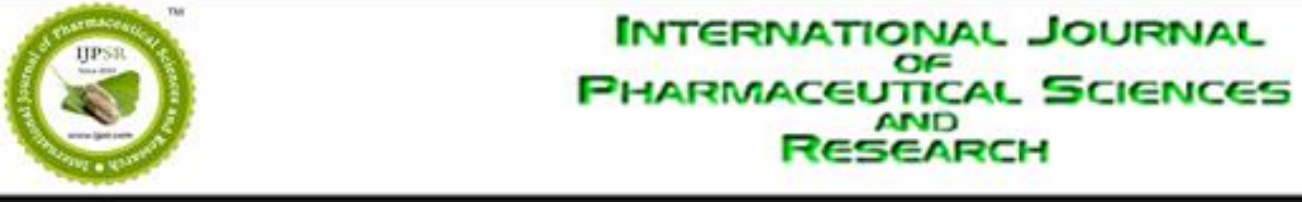

Received on 19 December, 2012; received in revised form, 19 January, 2013; accepted, 22 March, 2013

\title{
SPECTROPHOTOMETRIC METHOD FOR ESTIMATION OF CLOMIPRAMINE IN BULK AND TABLET DOSAGE FORM
}

Aitha Vijaya Lakshmi

Department of Chemistry, Sri Krishnadevaraya University, Kurnool - 518 001, Andhra Pradesh, India

Keywords:

Clomipramine (CP),

Spectrophotometry, DDQ $(2,3-$ dichloro 5,6-dicyano-1,4benzoquinone)

Correspondence to Author:

Dr. Aitha Vijaya Lakshmi

Department of Chemistry, Sri

Krishnadevaraya University, Kurnool

- 518 001, Andhra Pradesh, India

\begin{abstract}
A simple and sensitive spectrophotometric method has been developed for the determination of Clomipramine in bulk and tablet dosage forms. The method was based on the charge transfer reactions of Clomipramine with 2, 3-dichloro-5, 6-dicyano-1, 4-benzquinone. The absorbance of the highly intensive coloured solution was measured at $470 \mathrm{~nm}$ against reagent blank treated similarly. Beer's law is obeyed in the concentration range of $50-250 \mu \mathrm{g} / \mathrm{ml}$. Statistical analysis proves that the proposed method is reproducible and selective for the routine analysis of pharmaceutical formulations of Clomipramine.
\end{abstract}

E-mail: vijaya82.hari@gmail.com

INTRODUCTION: 2,3-Dichloro 5,6- dicyano- $\mathrm{p}$ benzoquinone (DDQ ) is an oxidizing ${ }^{1}$, dehydrating agent ${ }^{2}$ in synthetic organic chemistry as well as it is known for its interaction with drugs having donor sites in their structures, and form ion-pair charge transfer complexes which offers a basis for quantification of the drugs ${ }^{3-6}$.

Clomipramine (CP): Clomipramine chemically, 3(9-chloro-5, 6-dihydrobenzo [b][1]benzazepin-11yl)-N,N-dimethyl propan-1-amine. A tricyclic antidepressant similar to IMIPRAMINE that selectively inhibits the uptake of serotonin in the bin. It is readily absorbed from the gastrointestinal tract and demethylated in the liver to form its primary active metabolite, desmethylclomipramine. The structural formula of Clomipramine is given in fig. 1.

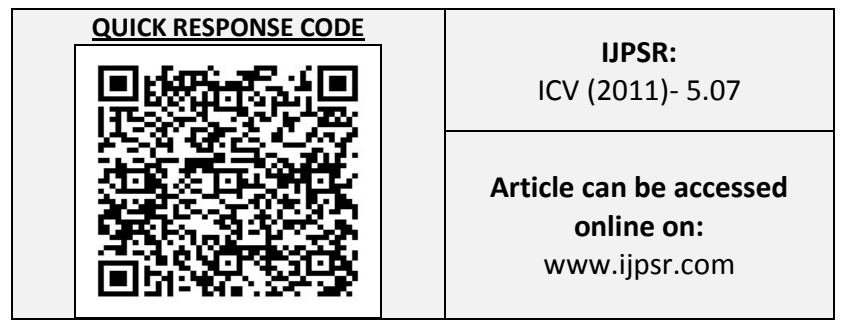

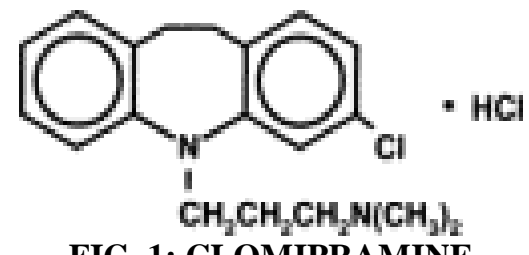

FIG. 1: CLOMIPRAMINE

Uses: It contain a fused three-ring moiety and are used in the treatment of depression.

Doses: Clomipramine Hydrochloride Capsules USP (25 mg, $50 \mathrm{mg}$, and $75 \mathrm{mg}$ ) [Mallinckrodt Inc.] Anafranil, (clomipramine hydrochloride capsules USP), is an antiobsessional drug that belongs to the class (dibenzazepine) of pharmacologic agents known as tricyclic antidepressants. Anafranil is available as capsules of 25,50 , and $75 \mathrm{mg}$.

Adverse effects: Dryness of mounth, drowsiness, increased sweating, sexual dysfunction, confusion, headache, tremors, dizziness, weight gain especially in women and palactorrhoea. Only a few methods viz, HPLC, Spectrofluorimetry, electrophoresis, UVvisible spectrophotometry appeared in the literature for the determination of Clomipramine in bulk and pharmaceutical formulations ${ }^{7}$. 
There is a need for simple spectrophotometric method for the analysis of clomipramine in pharmaceutical formulations. UV-Visible spectrophotometry is the technique of choice in research laboratories, hospitals and pharmaceutical industries due to its low cost and inherent simplicity.

The objectives of the work are to develop new spectrophotometric method for its estimation in bulk and tablet dosage form with good accuracy, simplicity, precission and economy. ence, the present work deals with the spectrophotometric estimation of Clomipramine using 2,3-dichloro 5,6-dicyano-1,4benzoquinone .

\section{MATERIALS AND METHODS:}

Instrumentation: After due calibration of the instrument, spectral and absorbance measurements are made using ELICO UV-160 A double beam Spectrophotometer manufactured by M/S ELICO private Limited, Hyderabad, India. All the chemicals used were of analytical grade. All the solutions were freshly prepared with double distilled water. Reagents were prepared a fresh for every method.

Preparation of Standard solution of drug: Pure clomipramine $(50 \mathrm{mg})$ is dissolved in $50 \mathrm{ml}$ methanol to obtain a stock solution of $1 \mathrm{mg} / \mathrm{ml}$. The final concentration of clomipramine is brought to $100 \mu \mathrm{g} / \mathrm{ml}$ with methanol.

\section{Preparation of Reagent:}

DDQ (0.1\% w/v): DDQ (2,3-dichloro 5,6-dicyano1,4-benzoquinone) (Loba Chem., India) solution is prepared by dissolving $100 \mathrm{mg}$ in $100 \mathrm{ml}$ of methanol.

Procedure: The wavelength of maximum absorbance of the Clomipramine drug treated with DDQ solution is ascertained by the following procedure. $1 \mathrm{ml}$ of Clomipramine solution $(100 \mu \mathrm{g} / \mathrm{ml})$ is transferred into a standard flask. To this solution $1.0 \mathrm{ml}$ of DDQ reagent is added to form honey colour solution. The final volume is brought to $10 \mathrm{ml}$ with chloroform. The resultant solution is mixed well and allowed to stand for $5 \mathrm{~min}$ for complete the reaction. The absorbance of the honey colour solution is measured at the wavelength range of 400 to $600 \mathrm{~nm}$, against the reagent blank (prepared in same manner omitting drug solution). The figure of absorbtion spectrum is given in fig. 2 .

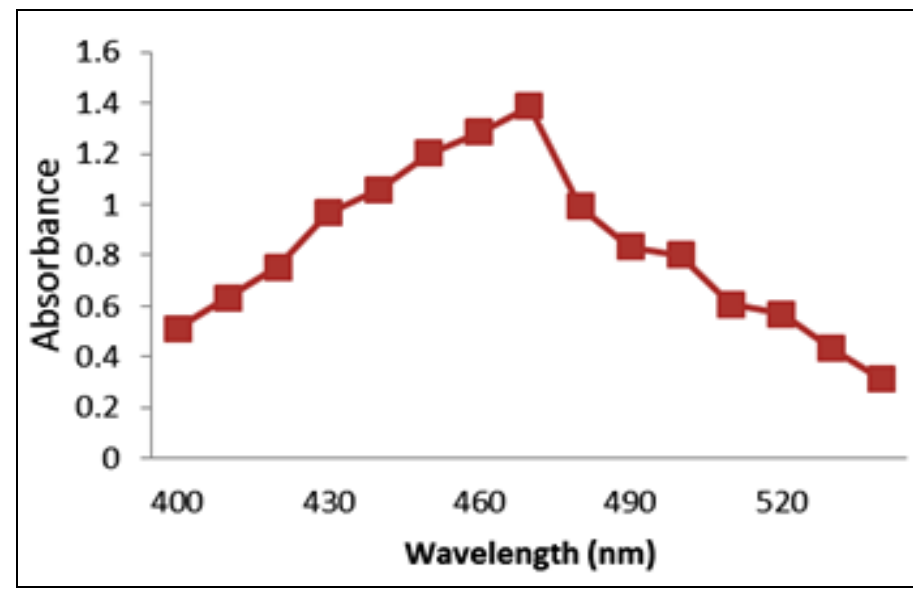

FIG. 2: SPECTRUM OF CLOMIPRAMINE-DDQ

From fig. 2, it is clear that the Clomipramine drug treated with DDQ solution has maximum absorbance at $470 \mathrm{~nm}^{8-11}$. Hence, all further studies are made at $470 \mathrm{~nm}$.

Assay Procedure: To study the effect of drug concentration on the absorbance of the charge transfer complex under optimal conditions now arrived is studied by the following method to know the suitability of the method for the assay of Clomipramine.

Various aliquots of the standard Clomipramine solution ranging from $0.5-2.5 \mathrm{ml}$ are transferred into a series of standard flasks. To each flask, $1.5 \mathrm{ml}$ of DDQ solution is added to produce honey colour. The final volume is brought to $10 \mathrm{ml}$ with chloroform.

The reaction mixture in each flask is shaken well and allowed to stand for $5 \mathrm{~min}$ to complete the reaction. The absorbance of the honey colour solution is measured at $470 \mathrm{~nm}$, against the reagent blank (prepared in similar manner omitting drug solution). Calibration graph is obtained by plotting absorbance values against the concentration of Clomipramine solution.

The calibration curve is found to be linear over a concentration range of 50 to $250 \mu \mathrm{g} / \mathrm{ml}$ of Clomipramine. The linearity of the curve obtained indicates that it obeys Beer's law. The amount of Clomipramine present in the sample is read from the calibration graph. The results are presented in fig. 3 .

Analysis of Tablets: The method is then applied to the determination of the drug from the marketed tablet formulations. Tablets are weighed and contents are powdered and well mixed. The powder equivalent to $50 \mathrm{mg}$ of Clomipramine is dissolved in 
chloroform, the volume is made upto $50 \mathrm{ml}$ with chloroform, filtered, residue is washed with chloroform. Further dilution is made as described in the preparation of standard solution of
Clomipramine. Further analysis is carried out as per procedure described above and results are summarized in Table 1. The amount of drug present in the sample is estimated from calibration graph.

TABLE 2: ASSAY OF CLOMIPRAMINE BY DDQ METHOD IN PHARMACEUTICAL FORMULATIONS

\begin{tabular}{lccccccc}
\hline Sample & $\begin{array}{c}\text { Labelled } \\
\text { amount } \\
(\mathbf{m g})\end{array}$ & $\begin{array}{c}\text { *Amount found by } \\
\text { Reference method } \pm \\
\text { S.D* }\end{array}$ & $\begin{array}{c}\text { *Amount found } \\
\text { by proposed method } \\
\mathbf{\pm} \text { S.D* }\end{array}$ & $\begin{array}{c}\text { \% of Label } \\
\text { claim }\end{array}$ & RSD\%* & $\mathbf{t}_{\text {*al }}$ & $\mathbf{F}^{*}$ \\
\hline Tablet1 & 25 & $24.966 \pm 0.014$ & $24.923 \pm 0.059$ & 99.692 & 0.236 & 0.453 & 1.431 \\
Tablet2 & 50 & $49.946 \pm 0.058$ & $49.913 \pm 0.051$ & 99.855 & 0.085 & 0.116 & 0.384 \\
Tablet3 & 75 & $74.845 \pm 0.308$ & $74.849 \pm 0.298$ & 99.849 & 0.298 & 0.284 & 0.443 \\
\hline
\end{tabular}

Average \pm Standard deviation of six determinations, the $\mathrm{t} \&$ F-values refer to comparision of the proposed method with reference method.



FIG. 3: CALIBRATION CURVE OF CLOMIPRAMINE

RESULTS AND DISCUSSION: The developed method based on the reaction of Clomipramine as $n$ electron donor with acceptor, 2, 3-dichloro-5, 6dicyano-1, 4-benzquinone. The absorption spectral analysis shows that the maximum absorbance of Clomipramine was found to be $470 \mathrm{~nm}$. It was observed that the absorbance started decreasing above $1.5 \mathrm{ml}$ of DDQ solution. Hence, $1.5 \mathrm{ml}$ of DDQ solution was used for further studies. The calibration curve was obtained for a series of concentration in the range of $50-250 \mu \mathrm{g} / \mathrm{ml}$. Statistical analysis was carried out and the results were found to be satisfactory. The recovery technique was performed to study the accuracy and reproducibility of the proposed method. The results are shown in Table 1.

The optical characteristics such as absorption maxima, Beer's law limits are presented in Table 2. The regression analysis using method of least squares was made for the slope (m), intercept (c) and correlation (r) obtained from different concentrations and results are summarized. The percent relative standard deviation, standard deviation and student's ' $t$ ' test values calculated from the six measurements of Clomipramine are presented in Table 1.
TABLE 1: OPTICAL CHARACTERISTICS

\begin{tabular}{cc}
\hline Parameters & Method - Value \\
\hline$\lambda_{\max }(\mathrm{nm})$ & 470 \\
Beer's law limit $(\mu \mathrm{g} / \mathrm{ml})$ & $50-250$ \\
Correlation coefficient $(\mathrm{r} 2)$ & 0.999 \\
Regression Equation & $\mathrm{y}=0.017 \mathrm{x}+0.005$ \\
$(\mathrm{y}=\mathrm{mx}+\mathrm{c})$ & 0.005 \\
Intercept $(\mathrm{c})$ & 0.017 \\
Slope $(\mathrm{m})$ & \\
\hline
\end{tabular}

Relative standard deviation values and standard deviation were low that indicates the reproducibility of the proposed method. In the student's ' $t$ ' test, no significant differences were found between the calculated and theoretical values of both the proposed methods at 95\% confidence level. The proposed method is found to be simple, precise, accurate and time saving, reproducible and can be conveniently adopted for routine analysis of estimation of Clomipramine in bulk drugs samples and pharmaceutical formulations.

CONCLUSION: The proposed method is found to be simple, precise, accurate, time saving and economic can be conveniently adopted for routine analysis of estimation of Clomipramine in bulk drug samples and pharmaceutical formulations as seen from the agreement of the amount of Clomipramine in the present method and the labeled amount of the pharmaceutical preparation.

ACKNOWLEDGEMENTS: The author is grateful to BAL Pharma Ltd, Bangalore, for providing pure drug samples, Department of Chemistry, S.K. University, Kurnool, A.P. for their continuous support and encouragement for providing the necessary infrastructure and facilities for executing this work. 


\section{REFERENCES:}

1. Braude. E.A, Linstead R.P and Wooldridge K. H. "Hydrogen Transfer. 9. The selective dehydrogenation of unsaturated alcohols by high-potential quinones". J Amer Chem Soc; $1956,3070-3074$.

2. Quancai $\mathrm{Xu}$, Zhengning $\mathrm{Li}$, and, Huiying Chen, A Convenient Synthesis of 2-Oxazolines and 2-Benoxazoles with PPh3-DDQ as the Dehydrating Reagent ,Chinese Journal of Chemistry 2011, 29 (5),:925-932.

3. Ghabsha T.S.A, Sabha T.N.A. and Mtaiwti S.M.A., Spectrophotometric determination of cephradine and cefadroxil using 2,3-dichloro5,6-dicyano-1,4-benzoquinone reagent,University of Sharjah Journal of Pure \& Applied Sciences, 2007, 4 (3),13-28.

4. Vmsi Krishna M and Gowri Sankar B, Utility of s and pacceptors for the spectrophotometric determination of Gemifloxacin mesylate in pharmaceutical formulations, EJournal of Chemistry. 2008, 5.(3),493-498.

5. Rehman N, Khan N.A. and Azmi S.N.H.,Validated spectrophotometricmethods for the determination of amiodarone hydrochloride in commercial dosage forms using p-chloranilic acid and 2,3-Dichloro -5,6-cyano-1,4benzoquinone. Analytical Sciences, 2004, 20, 1231-1235,

6. Frag E.Y., Mohamed G.G., Farag A.B. and Yussof E.B. Utility of $\pi$ and $\sigma$-Acceptor reagents for the Spectrophotometric Determination of Cefotaxime Sodium
Antibacterial Drug via Charge Transfer Complex Formation, Insight Pharmaceutical Sciences 2011, 1(4), 47-54.

7. Samiha A. Hussein, Michael E. El-Kommos, Hoda Y. Hassan and Abdel-Maboud I. Mohamed, Spectrophotometric determination of some dibenzazepine drugs by electrophilic coupling, Talanta, September 1989, Volume 36, Issue 9, 941-944.

8. A. S. Hammodi Spectrophotometric Determination of Rantidine- $\mathrm{HCl}$ in Pharmaceutical formulations IBN Alhaitham J. For pure and applied sciences vol.22 (2) 2009.

9. Tanveer A Wani1, Nasr Y Khalil1, Hamdy M AbdelRahman2 and Ibrahim A Darwish: Novel microwell-based spectrophotometric assay for determination of atorvastatin calcium in its pharmaceutical formulations Wani et al. Chemistry Central Journal 2011.

10. Arshiya Fathima Sayaji Rao and G. Venkateshwarlu: Spectrophotometric determination of drugs using 2,3 Dichloro 5,6 dicyano PBenzoquinone as Analytical reagent ,International Journal of ChemTech Research Vol.3, No.4, 1769-1780, Oct-Dec 2011.

11. K. B. Vinay, H. D. Revanasiddappa, M. S. Raghu, Sameer. A. M. Abdulrahman and N. Rajendraprasad: Spectrophotometric Determination of Mycophenolate Mofetil as Its Charge-Transfer Complexes with Two $\pi$ Acceptors Journal of Analytical Methods in Chemistry Volume 2012.

12. J. Inczedy, T. Lengyel, and A. M. Ure, IUPAC Compendium of Analytical Nomenclature: Definitive Rules, Blackwell Science, Boston, Mass, USA, 1998.

How to cite this article:

Lakshmi AV: Spectrophotometric method for estimation of Clomipramine in Bulk and Tablet Dosage Form Int J Pharm Sci Res 2013; 4(4); 1610-1613. 